\title{
Bioética e Estratégia Saúde da Família: a perspectiva dos Agentes Comunitários de Saúde
}

\author{
Selma Vaz Vidal, Andréia Patrícia Gomes, Rodrigo Siqueira-Batista
}

\section{RESUMO}

Identificar os principais problemas bioéticos na Estratégia Saúde da Família (ESF), na perspectiva dos Agentes Comunitários de Saúde (ACS) do Município de Magé, RJ como subsídio para a proposição de estratégias de formação dirigidas ao amadurecimento da tomada de decisão frente aos conflitos bioéticos - foi o escopo do presente artigo. Participaram da pesquisa 124 ACS das 62 equipes da ESF. Aplicouse um questionário, em dezembro 2013, com 22 questões, divididas em três seções: (1) características gerais; (2) problemas bioéticos enfrentados pelo ACS em serviço e (3) conhecimento sobre os conceitos de ética e bioética e sobre os modos de aprendêla. As respostas foram apreciadas por meio da técnica de análise de conteúdo. Identificaram-se o perfil dos ACS e os principais problemas bioéticos presentes em seu cotidiano. A educação permanente foi uma aposta orientadora do diálogo para o aprimoramento das competências morais desses trabalhadores, elemento essencial para o melhor enfrentamento dos conflitos.

Palavras-chave: Bioética; Estratégia Saúde da Família; Agente Comunitário de Saúde.

\section{Andréia Patrícia Gomes (Universidade Federal de Viçosa, Viçosa, MG, Brasil) \\ Rodrigo Siqueira-Batista (Universidade Federal de Viçosa, Viçosa, MG, Brasil)}

(Faculdade Dinâmica do Vale do Piranga, Ponte Nova, MG, Brasil)

\section{ABSTRACT}

Identifying the main bioethical problems in the Family Health Strategy (FHS), from the perspective of Community Health Agents (CHA) of the municipality of Magé, RJ - as a subsidy for the proposition of training strategies aimed at maturing decision-making in the face of bioethical conflicts - was the scope of this article. The study was conducted 124 CHA from the 62 teams of the FHS. We applied a questionnaire in December 2013, which comprised 22 questions divided into three main sections: (1) general characteristics, (2) bioethical problems faced by the CHA in service and (3) knowledge about the concepts of ethics and bioethics and the ways to learn it. The answers were evaluated using the content analysis technique. The profile of CHA and the main bioethical problems present in their daily lives were identified. Permanent Education was a guiding bet of dialogue for the improvement of the moral skills of these workers, an essential element for better coping with conflicts.

Keywords: Bioethics; Family Health Strategy; Community Health Agent.
Correspondência para:

Rodrigo Siqueira-Batista rsbatista@ufv.br 


\section{INTRODUÇÃO}

O trabalho na Estratégia Saúde da Família (ESF) - inscrita na Atenção Primária à Saúde (APS) - é um desafio cotidiano que instiga o profissional a contribuir para a transformação da realidade, tendo em vista o complexo processo de consolidação do Sistema Único de Saúde (SUS) (DOURADO et al., 2020; SIQUEIRA-BATISTA et al., 2013). Com efeito, os profissionais de saúde devem (re)conhecer as características ambientais, culturais, econômicas, políticas, sanitárias e sociais - entre outras - das populações dos territórios, as quais influenciam diretamente a história de vida das pessoas e determinam formas de perceber, experimentar e vivenciar a saúde, a doença e o cuidado (MONKEN; GONDIM, 2016).

O território próprio da ESF - cenário dessa nova geografia - permite a emergência de interações muito próprias, com destaque para as interseções estabelecidas envolvendo (i) os profissionais entre si, (ii) os profissionais e os usuários / as famílias e (iii) os profissionais e os usuários / as famílias com os dispositivos dos sistemas locais de saúde. É esperado, pois, que toda uma nova ordem de problemas bioéticos se estabeleça - nova, em relação às questões "tradicionais" presentes em outros espaços de cuidado, como os hospitais -, os quais precisarão ser abordados, tendo em vista as estratégias para educação dos profissionais de saúde no campo da bioética (GOMES et al., 2016).

Neste cenário, pensar e pôr em ação a caixa de ferramentas da bioética torna-se essencial para que o trabalho se dê de forma exitosa, pois, intervenções pontuais certamente não serão tão eficientes quanto as ações longitudinais e continuadas (SIMAS et al., 2019). A assimilação de conceitos fundamentais, teorias e métodos pelos profissionais - é considerada ainda incipiente (MOTTA, 2012). Mais tempo e trabalho são necessários para essa aproximação e para a agregação dos conhecimentos ao repertório dos trabalhadores e da equipe (GOMES et al., 2016).
Desde esta perspectiva, cabe destaque para os pontos de vista dos Agentes Comunitários de Saúde (ACS), partícipes da equipe que, por sua pertença social a mesma área na qual trabalham, estão inseridos em uma situação de dupla via: (a) como orientadores sociais da APS/ESF, por disponibilizar aos cidadãos o cuidado longitudinal em saúde; e (b) como facilitadores da equipe, na medida em que podem encaminhar as demandas que englobam a garantia dos direitos dos cidadãos, na conjuntura inclusiva das políticas públicas. 0 trabalho no cenário da APS/ESF, com enfoque especial na atuação dos ACS, deve passar, necessariamente, pelo reconhecimento de que o papel desses profissionais se exprime, plenamente, no encontro com a comunidade e na construção de liames afetivos, firmados por meio do mútuo acolhimento entre ACS e usuários (BRASIL, 2016).

Como os ACS veem a emergência de problemas bioéticos na APS/ESF? Como abordam tais problemas? Como gostariam de se educar para lidar com eles? Essas perguntas, apesar de instigantes, têm incipiente abordagem na literatura. Na tentativa de colaborar para o esclarecimento desse campo pouco explorado, empreendeu-se a presente investigação, cujo objetivo geral foi a identificação dos principais problemas bioéticos na APS/ESF, na perspectiva dos ACS do Município de Magé, Estado do Rio de Janeiro, como subsídio para a ulterior proposição de estratégias de formação dirigidas ao amadurecimento da tomada de decisão frente os conflitos éticos.

\section{PERCURSO METODOLÓGICO}

O estudo foi conduzido no município de Magé, estado do Rio de Janeiro - em dezembro de 2013 - o qual contava, à época, com 62 equipes básicas da APS/ESF (albergando 458 ACS), representando uma cobertura de 78\% (BRASIL, 2013).

Os participantes do estudo foram 124 ACS que assinaram o Termo de Consentimento Livre e Esclarecido (TCLE), após serem informados (i) dos riscos e dos benefícios da investigação, (ii) 
da garantia ao sigilo e (iii) do compromisso com as diretrizes da Resolução CNS/MS no 466/12. O instrumento de investigação foi um questionário autoaplicável com 22 questões, divididas em três seções. O tratamento dos dados foi realizado mediante a técnica de análise de conteúdo (BARDIN, 2010).

O estudo foi parte dos resultados da tese de doutorado "Educação em Bioética na Estratégia Saúde da Família: uma aposta na paideia", apresentada ao Programa de Pós-Graduação em Bioética, Ética Aplicada e Saúde Coletica (PPGBIOS) da Universidade Federal do Rio de Janeiro (UFRJ). O projeto foi aprovado pelo Comitê de Ética em Pesquisa (CEP) do Instituto de Estudos em Saúde Coletiva da UFRJ, sob o № CAAE 19038213.9.0000.5286, após a Secretaria de Saúde do Município de Magé, autorizar a realização da pesquisa.

\section{RESULTADOS E DISCUSSÃO}

A apresentação dos resultados está dividida de acordo com as três seções do questionário, discutidas à luz da literatura pertinente.

\section{CARACTERÍSTICAS GERAIS DOS PARTICIPANTES DA PESQUISA}

Essa primeira etapa constou de seis perguntas de caracterização dos participantes do estudo ( $n=124)$, cuja idade variou entre 18 e 64 anos. Dentre os ACS, 104 (freq. rel. = 83,9\%) declararam ser do sexo feminino e 20 participantes (freq. rel. $=16,1 \%$ ) do sexo masculino. Com relação à predominância feminina dos ACS, David (2011) estabelece pertinente discussão com foco na situação socioeconômica da mulher ao longo do século $X X$, a qual tem implicação em termos laborais:

"De maneira geral, as mulheres se sentiam atraídas pelo trabalho de agentes; eram casadas, com filhos e conciliavam alguma atividade doméstica para gerar renda, como fazer e vender doces e salgados, costurar, ou algum serviço a terceiros - faxinas, tomar conta de crianças, cuidar de idosos à noite. Algumas, com escolaridade mais avançada, ministravam aulas particulares às crianças com dificuldades na escola, quando também aproveitavam para 'ensinar higiene e bons costumes', no dizer de uma delas. Esta preocupação especial com as crianças é uma característica marcante das agentes que conhecemos nesses anos" (DAVID, 2011, p. 61).

Portanto, socialmente, persiste a situação da mulher que diariamente exerce múltiplos papéis desde os serviços domésticos, até o trabalho remunerado fora do lar, passando pela educação dos filhos. Em muitos casos, a mulher que reside nas comunidades do território da APS/ESF, com pouca qualificação técnica, está à procura de oportunidades de trabalho e de geração de renda, mesmo com remuneração menor, desde que seja próxima à sua residência, devido à conciliação com as demais atribuições socialmente impostas. Regra geral, as ACS femininas seguem esse perfil, justificando a predominância deste gênero na APS/ESF.

Os resultados referentes à escolaridade dos ACS podem ser visualizados na Tabela 1.

As Escolas Técnicas e os Centros Formadores do SUS ofertam, através do "Programa Saúde com Agente", cursos destinados à formação técnica completa dos ACS (BRASIL, 2020). Este é um profissional que atua na educação em saúde, participa da organização do trabalho coletivo, colabora para o planejamento e a execução das ações interdisciplinares e para a educação popular em saúde. O Ministério da Saúde financia nacionalmente o curso técnico de ACS em duas das três etapas sequenciais, desde a publicação do referencial curricular nacional do curso, em 2004 (BRASIL, 2016). 
Tabela 1 - Escolaridade dos ACS participantes da pesquisa. Magé/RJ, dez/2013.

\begin{tabular}{lccc}
\hline Escolaridade & Frequência absoluta & Frequência relativa \\
\hline Ensino Fundamental Completo & 6 & $4,8 \%$ \\
Ensino Fundamental Incompleto & 4 & $3,2 \%$ \\
Ensino Médio Completo & 95 & $76,6 \%$ \\
Ensino Médio Incompleto & 9 & $7,3 \%$ \\
Ensino Superior Completo & 2 & $1,6 \%$ \\
Ensino Superior Incompleto & 8 & $6,5 \%$ \\
\hline Total & 124 & $100,0 \%$ \\
\hline
\end{tabular}

Fonte: elaborada pelos autores.

Com relação à pergunta referente ao tempo de exercício do ACS na APS/ESF houve predomínio do intervalo de meses a um ano. Isto pode caracterizar duas situações na gestão do trabalho no serviço público: (1) posse de novos concursados para o cargo de ACS e (2) vínculo de trabalho firmado por contrato administrativo temporário. Este último contexto não é desejável, pois, gera instabilidade para o trabalhador, quebra de vínculo e descontinuidade no cuidado longitudinal às famílias, com a ocorrência da rotatividade profissional.

\section{PROBLEMAS BIOÉTICOS ENFRENTADOS PELA EQUIPE}

$\mathrm{Na}$ análise desta seção reuniram-se as perguntas, a fim de sintetizar em um quadro demonstrativo as respostas dos participantes da pesquisa. A apreciação das questões foi inspirada no estudo de Zoboli e Fortes (2004) e Motta (2012).

Os participantes comentaram que recorreram aos profissionais da equipe da APS/ESF e a equipe gestora para dirimir problemas éticos. Outrossim,
“[...] a realidade da atenção primária exige uma ética hermenêutica que interprete e reflita criticamente a partir da própria facticidade do contexto em que acontecem os problemas éticos, configurando-os como desafios éticos base para encontrar os caminhos de solução" (JUNGES; BARBIANI, 2013, p. 208).

Foram citadas, pelos ACS, iniciativas individuais consultas a artigos científicos, livros, internet, códigos de ética - no sentido de solucionar os problemas bioéticos identificados; todavia, a maioria dos que responderam a esta pergunta apontou o trabalho da equipe de APS/ESF, e da própria gestão da saúde, como núcleo de acolhimento destes conflitos.

À guisa de proposição cabe à sugestão de criação de um Comitê de Bioética Municipal (SIMAS et al., 2019), quiçá dirigido à apreciação de questões dos três níveis de atenção, com ênfase na APS/ESF. Tal poderia ser um modo de subsidiar as decisões dos profissionais envolvidos. 
Quadro 1 - Principais categorias de problemas bioéticos identificados pelos ACS, suas consequências, aspecto mais marcantes, abordagem pela equipe e solução (se houve). Magé/RJ, julho de 2013.

\begin{tabular}{|c|c|c|c|}
\hline \multirow{4}{*}{$\begin{array}{l}\text { PROBLEMAS } \\
\text { ÉTICOS } \\
\text { NA RELAÇÃO } \\
\text { COM } \\
\text { O USUÁRIO E } \\
\text { FAMÍLIA }\end{array}$} & $\begin{array}{l}\text { SITUAÇÃO IDENTIFICADA } \\
\text { COMO PROBLEMA ÉTICO E } \\
\text { BIOÉTICO PELO ACS }\end{array}$ & $\begin{array}{c}\text { CONSEQUÊNCIAS E } \\
\text { ASPECTO MARCANTE DO } \\
\text { PROBLEMA }\end{array}$ & $\begin{array}{l}\text { ABORDAGEM DA } \\
\text { EQUIPE E SOLUÇÃO } \\
\text { DO PROBLEMA }\end{array}$ \\
\hline & $\begin{array}{l}\text { Impaciência do usuário no } \\
\text { atendimento }\end{array}$ & $\begin{array}{l}\text { Desgaste do profissional na } \\
\text { relação com o usuário }\end{array}$ & $\begin{array}{l}\text { Diálogo com } \\
\text { usuário }\end{array}$ \\
\hline & $\begin{array}{l}\text { Desrespeito do usuário para } \\
\text { com o profissional }\end{array}$ & $\begin{array}{l}\text { Fugir do controle e se tornar } \\
\text { uma situação pessoal }\end{array}$ & $\begin{array}{l}\text { Acionamento da } \\
\text { polícia }\end{array}$ \\
\hline & $\begin{array}{l}\text { Vestimenta inadequada do } \\
\text { usuário na unidade }\end{array}$ & Desrespeito ao profissional & $\begin{array}{l}\text { Fixação de cartaz } \\
\text { com informação } \\
\text { sobre a vestimenta } \\
\text { adequada à } \\
\text { unidade }\end{array}$ \\
\hline \multirow{8}{*}{$\begin{array}{l}\text { PROBLEMAS } \\
\text { ÉTICOS } \\
\text { NA RELAÇÃO } \\
\text { ENTRE OS } \\
\text { MEMBROS DA } \\
\text { EQUIPE DA ESF }\end{array}$} & $\begin{array}{l}\text { Conduta crítica entre } \\
\text { funcionários ("fofoca") }\end{array}$ & $\begin{array}{l}\text { Clima hostil na unidade; } \\
\text { prejuízo da equipe da ESF }\end{array}$ & Reunião de equipe \\
\hline & $\begin{array}{l}\text { Falta de compromisso } \\
\text { profissional }\end{array}$ & Falta de companheirismo & Reunião de equipe \\
\hline & Quebra de sigilo profissional & $\begin{array}{l}\text { Problemas com a } \\
\text { comunidade }\end{array}$ & $\begin{array}{l}\text { Reunião com } \\
\text { advertência verbal }\end{array}$ \\
\hline & $\begin{array}{l}\text { Desrespeito entre } \\
\text { funcionários com agressão } \\
\text { (na presença do usuário) }\end{array}$ & $\begin{array}{l}\text { Acontecimento grave, sem } \\
\text { consequências para o } \\
\text { agressor }\end{array}$ & $\begin{array}{l}\text { Relatório para a } \\
\text { gestão; o caso não } \\
\text { foi resolvido }\end{array}$ \\
\hline & $\begin{array}{l}\text { Supervisão dos ACS com } \\
\text { críticas e ameaças }\end{array}$ & $\begin{array}{l}\text { Prejuízo no desempenho da } \\
\text { equipe }\end{array}$ & Não houve solução \\
\hline & $\begin{array}{l}\text { Quebra da confiabilidade } \\
\text { profissional }\end{array}$ & Descrédito da equipe da ESF & Reunião de equipe \\
\hline & $\begin{array}{l}\text { Conduta inadequada do } \\
\text { profissional com o usuário }\end{array}$ & $\begin{array}{l}\text { Desligamento do } \\
\text { profissional da unidade }\end{array}$ & Reunião de equipe \\
\hline & $\begin{array}{l}\text { Desencontro de } \\
\text { informações e imprudência } \\
\text { na abordagem social }\end{array}$ & $\begin{array}{l}\text { Conduta profissional } \\
\text { inadequada }\end{array}$ & Reunião de equipe \\
\hline \multirow{2}{*}{$\begin{array}{l}\text { PROBLEMAS } \\
\text { ÉTICOS } \\
\text { COM A } \\
\text { ORGANIZAÇÃO } \\
\text { E O SISTEMA DE } \\
\text { SAÚDE }\end{array}$} & $\begin{array}{l}\text { Falta de medicação na } \\
\text { unidade }\end{array}$ & \multirow[b]{2}{*}{ Descrédito na saúde local } & \multirow{2}{*}{$\begin{array}{l}\text { Conversar com o } \\
\text { usuário para } \\
\text { explicar a situação } \\
\text { Resolução urgente } \\
\text { do problema }\end{array}$} \\
\hline & $\begin{array}{l}\text { Dificuldade na marcação de } \\
\text { consultas e exames e } \\
\text { demora na entrega de } \\
\text { resultados }\end{array}$ & & \\
\hline
\end{tabular}

Fonte: elaborada pelos autores. 


\section{CONHECIMENTO SOBRE OS CONCEITOS DE ÉTICA E DE BIOÉTICA}

Na pergunta sobre o conhecimento dos ACS de conceitos de ética e de bioética, 85 participantes $(n=124)$ declararam que sim (freq. rel. $=68,5 \%$ ) e 39 ACS disseram não (freq. rel. = $31,5 \%$ ). Aspectos relevantes sobre a ética, mencionado pelos participantes, disseram respeito ao sigilo, à conduta ética dos profissionais e à deontologia como conjunto de deveres, princípios e normas adotadas por um determinado grupo profissional (MOTTA, 2012).

$\mathrm{Na}$ abordagem dos ACS - com relação ao entendimento sobre ética e bioética emergiram da análise duas categorias, fundamentadas pelas respostas dos participantes, as quais englobaram as ocorrências textuais produzidas. Destacaram-se as seguintes respostas para a visualização da composição das categorias:

\section{1a - Ética: "um conjunto de ações morais que estão presentes em todos os setores da vida".}

ACS 26 - “...na educação, na política, no cotidiano de cada um".

ACS 40 - "Ser honesto em meu ambiente de trabalho, ter respeito, sigilo, comportamento adequado, ser organizado".

\section{2a - Bioética: "Ética aplicada e prática que visam o enfrentamento dos conflitos e controvérsias morais"}

ACS 6 - "Estudo sistemático das dimensões morais incluindo visão moral, decisão e conduta política".

ACS 12 - "É uma ciência biológica que investiga as condições necessárias para a administração responsável da vida humana".
Dos participantes do estudo, 82 (freq. rel. = $66,1 \%)$ declararam contato prévio com conceitos bioéticos, tais como respeito à autonomia, beneficência, não-maleficência, justiça, proteção e compaixão (REGO et al., 2020). Responderam "não" 30 pessoas (freq. rel. $=24,2 \%$ ) e 12 (freq. rel. =9,7\%) participantes deixaram a resposta em branco.

$\mathrm{Na}$ análise da questão relativa à percepção do ACS sobre a afirmação de que todos os profissionais de saúde devem ter seu trabalho pautado nos princípios da ética e da bioética, com comentários do total de participantes ( $\mathrm{n}=$ 124), 106 ACS (freq. rel. $=85,5 \%$ ) disseram que concordam com a referida proposição; outros 14 ACS (freq. rel. =11,3\%) não teceram comentários; e quatro participantes (freq. rel. = $3,2 \%)$ declararam não concorda com a afirmativa. Deve ser destacado que o ACS é um profissional exclusivo da APS/ESF e, como tal, deve ter seu trabalho embasado por legislação específica para sua profissão. O código de ética profissional dos ACS encontra-se na fase de efetivação legal, no site do Conselho Nacional dos Técnicos em Agentes Comunitários de Saúde (CONTACS, 2021).

Consultou-se os participantes sobre a possibilidade de aprender ética e bioética e, em caso afirmativo, de qual modo. A maioria dos ACS (97/124) respondeu que "sim" (freq. rel. = 78,2\%), mediante "atitude", "capacitação" e "trabalho em equipe", enquanto 16 (freq. rel. = $13,0 \%$ ) participantes disseram que "não" é possível aprendê-las. Deixaram a questão em branco, 11 participantes (freq. rel. = 8,8\%). Deve ser ponderado que o debate sobre a "natureza" e a possibilidade de ensino da ética remonta à Antiguidade helênica. Platão, filósofo grego que se dedicou sobremaneira a este assunto, inicia um de seus mais importantes diálogos, o Mênon, com as seguintes questões: $a$ virtude é coisa que se ensina? Ou não é coisa que se ensina, mas que se adquire pelo exercício? Ou nem coisa que se adquire pelo exercício nem coisa que se aprende, mas algo que advém aos homens por natureza ou por alguma outra maneira? Dois mil e quinhentos anos se passaram e tais questões permanecem ecoando na cultura ocidental (PLATÃO, 2001). 
A efetividade do processo educacional, por exemplo, deve ser pensada em termos da sua intencionalidade, remetendo não à transmissão de conteúdos morais específicos, mas ao exercício da autonomia, por meio de práticas pedagógicas que promovam a práxis decisória eticamente orientada, visando à coerência dos argumentos que fundamentam suas ações (COSTA \& SIQUEIRA-BATISTA, 2004). É fundamental, pois, que os ACS, nas diversas etapas formativas percorridas, associem prioritariamente $\mathrm{o}$ desempenho de suas atribuições nas atitudes e tomada de decisão, com a ética a serviço da vida.

\section{CONSIDERAÇÕES FINAIS}

A descrição dos principais problemas bioéticos, na perspectiva dos ACS de Magé, Rio de Janeiro, permitiu a identificação de situações persistentes investigadas em outros estudos dirigidos às questões éticas na APS/ESF, especialmente no que concerne aos conflitos nas relações (1) entre usuário/família e equipe, (2) entre os membros da equipe e (3) atinentes à organização do sistema de saúde.

Em respeito à identificação, junto aos ACS, das concepções referentes à ética e à bioética, foram associados os problemas vivenciados com determinadas correntes teóricas das disciplinas: principialismo, utilitarismo, casuística, deontologia. A problematização da realidade representou campo profícuo para o compartilhamento dos saberes, quando a educação está perfeitamente articulada ao serviço.

A pesquisa balizou algumas proposições nos termos da práxis de educação permanente para (i) a constituição de saberes (ii) o exercício do (re)conhecimento e da argumentação acerca dos problemas éticos e bioéticos na APS, com a aposta na construção de competências morais para o trabalho na APS/ESF.

Trabalho subsidiado pelo CNPq. 


\section{REFERÊNCIAS}

BARDIN, Laurence. Análise de conteúdo. 4. ed. ampl. e rev. Lisboa, Portugal: Edições 70, 2010. 281 p.

BRASIL. Ministério da Saúde. Portaria MS № 3.241, de 7 de dezembro de 2020. Institui o Programa Saúde com Agente, destinado à formação técnica dos Agentes Comunitários de Saúde e dos Agentes de Combate às Endemias. Disponível em <https://www.in.gov.br/en/web/dou/-/portaria-ms-n-3.241-de-7de-dezembro-de-2020-293178860>. Acesso em: 3 dez. 2020.

BRASIL. Ministério da Saúde. Diretrizes para capacitação de agentes comunitários de saúde em linhas de cuidado. Secretaria de Gestão do Trabalho e da Educação na Saúde. Brasília: Ministério da Saúde, 2016. 46 p. Disponível em: <http://bvsms.saude.gov.br/bvs/publicacoes/diretrizes capacitacao agentes comunitarios cuidado.pdf Acesso em 17 dez. 2020.

BRASIL. Ministério da Saúde. CNES - 12/2013. Disponível em <http://tabnet.datasus.gov.br/cgi/cnes/NT EquipesSa\%C3\%BAde.htm>. Acesso em: 04 jan. 2014.

CONTACS. Conselho Nacional de Técnicos em Agentes Comunitários de Saúde. 2021. Disponível em <https://contacs.org.br/>. Acesso em: 11 fev. 2021.

COSTA, C. R. B. S. F.; SIQUEIRA-BATISTA, R. As teorias do desenvolvimento moral e o ensino médico: uma reflexão pedagógica centrada na autonomia do educando. Revista Brasileira de Educação Médica, v. 28, n. $3, \quad$ p. 242-250, $2004 . \quad$ Disponível em <https://www.scielo.br/scielo.php?script=sci arttext\&pid=S0100-55022004000300242>. Acesso em: 2 jan. 2016

DAVID, H. M. S. L. Educação em saúde e o trabalho dos agentes comunitários de saúde. In: MIALHE, F.L. O agente comunitário de saúde: práticas educativas. Campinas, SP: Editora UNICAMP, 2011. 150 p.

DOURADO, J. V. L.; AGUIAR, F. A. R.; LOPES, R. E.; SILVA, M. A. M.; FERREIRA JÚNIOR, A. R. Problemas éticos vivenciados por enfermeiros na Estratégia Saúde da Família. Revista Bioética, v. 28, n. 2, p. 356-364, 2020. Disponível em: $\quad$ http://www.scielo.br/scielo.php?script=sci_arttext\&pid=S198380422020000200356\&lng=pt\&nrm=iso >. Acesso em: 14 dez. 2020.

GOMES, A. P.; GONÇALVES, L. L.; SOUZA, C. R.; SIQUEIRA-BATISTA, R. Estratégia Saúde da Família e bioética: grupos focais sobre trabalho e formação. Revista Bioética, v. 24, n. 3, p. 488-494, 2016. Disponível em: <https://www.scielo.br/scielo.php?script=sci arttext\&pid=S1983-80422016000300488>.

Acesso em: 14 dez. 2020.

JUNGES, J. R.; BARBIANI, R. Interfaces entre território, ambiente e saúde na atenção primária: uma leitura bioética. Revista Bioética, v. 21, n. 2, p. 207-217, 2013. Disponível em: $<$ http://www.scielo.br/scielo.php?script=sci arttext\&pid=S1983$\underline{80422013000200003 \& \operatorname{lng}=e n \& n r m=i s o}>$. Acesso em: 14 dez. 2020.

MONKEN, M.; GONDIM, G. M. M. Território: o lugar onde a vida acontece. In: BORNSTEIN, V. J. Curso de Aperfeiçoamento em Educação Popular em Saúde: textos de apoio. Rio de Janeiro: EPSJV, 2016. 164 p.

MOTTA, L. C. S. O Cuidado no Espaço-Tempo do Oikos: Sobre a Bioética e a Estratégia Saúde da Família. Junho/2012. 119 f. Dissertação (Mestrado) - UFRJ. Programa de Pós-Graduação em Bioética, Ética Aplicada e Saúde Coletiva, Rio de Janeiro, 2012. 
PLATÃO. Mênon. Texto estabelecido por John Burnet e tradução de Maura Iglésias. Rio de Janeiro: PUCRio/Loyola, 2001.

Disponível

em <https://edisciplinas.usp.br/pluginfile.php/3975434/mod resource/content/1/Texto\%20PI at\%C3\%A3o M\%C3\%AAnon.pdf>. Acesso em 20 jan 2021.

REGO, S.; PALÁCIOS, M.; SIQUEIRA-BATISTA, R. Bioética para profissionais de saúde. 2a reimp Rio de Janeiro: Editora FIOCRUZ, 2020. 160 p.

SIMAS, K. B. F.; GOMES, A. P.; FERREIRA, M. L. A.; RODRIGUES, D. D.; SIQUEIRA-BATISTA, R. Comissão de Bioética e Atenção Primária à Saúde: uma proposta dirigida à realidade carioca. In: PALÁCIOS, M. Bioética, saúde e sociedade. Rio de Janeiro: Editora Fiocruz, 2019, p. 113-127.

SIQUeIRA-BAtISTA, R.; GOMES, A. P.; AlbuQUERQUE, V. S.; CAVAlCANTI, F. O. L.; COTTA, R. M. M. Educação e competências para o SUS: é possível pensar alternativas à(s) lógica(s) do capitalismo tardio? Ciência \& Saúde Coletiva, v. 18, n. 1. p. 159-170, 2013. Disponível em: $<$ https://www.scielo.br/scielo.php?pid=S141381232013000100017\&script=sci abstract\&tlng=pt>. Acesso em 20 jan 2021.

ZOBOLI, E. L.C. P.; FORTES, P. A. C. Bioética e atenção básica: um perfil dos problemas éticos vividos por enfermeiros e médicos do Programa Saúde da Família, São Paulo, Brasil. Cadernos de Saúde Pública, v. 20, n. 6, 2004. Disponível em <https://www.scielo.br/scielo.php?pid=S0102-

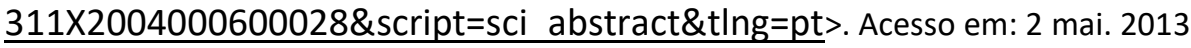

